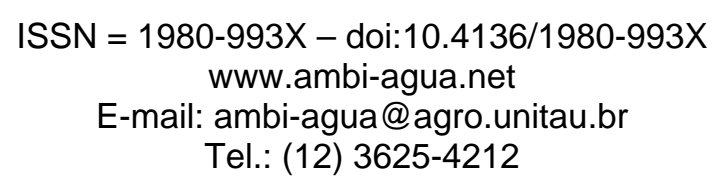

\title{
Influência do uso e ocupação do solo na qualidade da água: um método para avaliar a importância da zona ripária
} (doi:10.4136/ambi-agua.177)

\author{
Raul Candido da Trindade Paixão Coelho ${ }^{1}$; Iuri Buffon² ${ }^{2}$ Teresinha Guerra ${ }^{3}$ \\ ${ }^{1}$ Instituto Chico Mendes de Conservação da Biodiversidade - ICMBio \\ E-mail: raul.coelho@icmbio.gov.br \\ ${ }^{2}$ Universidade Estadual do Rio Grande do Sul - UERGS \\ E-mail: iuribuffon@gmail.com \\ ${ }^{3}$ Universidade Federal do Rio Grande do Sul - UFRGS \\ E-mail: tg@ufrgs.br
}

\section{RESUMO}

O ecossistema ripário constitui uma interface entre o ambiente terrestre e o aquático nas bacias hidrográficas. O impacto ambiental antropogênico nas áreas ribeirinhas e bacias de drenagem influencia a biota e a qualidade das águas correntes. O objetivo deste trabalho foi avaliar o efeito desse impacto, representado pelos diferentes usos do solo nas bacias de drenagem e nas áreas ripárias, na qualidade da água. Classificou-se o uso do solo com a interpretação de imagens de satélites e levantamento de dados a campo e os resultados foram avaliados com um índice de antropização adaptado para tal finalidade. Analisou-se a água nos cursos d’água com amostras mensais no período de julho de 2006 a junho de 2007, e se avaliou a qualidade com um índice composto pelos parâmetros: oxigênio dissolvido, $\mathrm{pH}$, turbidez, sólidos dissolvidos totais e sólidos suspensos totais. Correlacionando os índices do uso do solo das áreas ripárias com os índices de qualidade da água, um $\mathrm{r}^{2}$ de 0,64 foi obtido e este é superior ao $\mathrm{r}^{2}$ de 0,23 obtido na correlação entre os índices de ocupação do solo da área de toda a bacia de drenagem e os respectivos índices de qualidade da água, o que salienta a importância preponderante da área ripária na qualidade da água e cria a perspectiva de um novo método de análise da situação ambiental.

Palavras-chave: unidade de conservação; área de preservação permanente; bacia hidrográfica; Floresta Nacional de Canela.

\section{Influence of the land use and land cover on the water quality: a method to evaluate the importance of riparian zones}

\begin{abstract}
The riparian ecosystem constitutes an interface among the terrestrial and aquatic environments in a watershed. The human impact on drainage basins influences the organisms and the quality of the running water. The objective of this paper was to evaluate the effect of this impact, taking into account the different land use classes of the drainage basins and of the riparian areas in the quality of the water. Land use and land cover of the watershed were classified based on the interpretation of satellite imagery and field work in the riparian areas and the results were evaluated with an index adapted for such purpose. A sample of the of the water courses was collected monthly in the period of July of 2006 to June of 2007, and the quality was evaluated with an index composed using the parameters: dissolved oxygen, $\mathrm{pH}$, turbidity, total dissolved solids and total suspended solids. A correlation coefficient of $\mathrm{r}^{2} 0.64$ was observed between land use of the riparian areas with the quality of the water. This value was higher than the correlation coefficient between the land use indices and the respective
\end{abstract}


COELHO, R. C. T. P.; BUFFON, I.; GUERRA, T. Influência do uso e ocupação do solo na qualidade da água: um método para avaliar a importância da zona ripária. Ambi-Agua, Taubaté, v. 6, n. 1, p. 104-117, 2011. (doi:10.4136/ambi-agua.177)

indices of water quality of the whole watershed $\left(r^{2}=0.23\right)$, pointing out the preponderant importance of the land use and land cover in the riparian areas in the quality of the water and showing a perspective of a new method for the analysis of the environmental condition.

Keywords: conservation unit; legally protected areas; watershed; National Forest of Canela.

\section{INTRODUÇÃO}

Para o desenvolvimento sustentável da humanidade são necessárias as práticas de exploração dos recursos naturais que aliam princípios de preservação e conservação do meio ambiente, atendendo às necessidades do presente sem comprometer a capacidade de atendimento das futuras gerações (Word Commission on Environmental and Development, 1987).

Além de considerar os aspectos econômicos e sociais, esse desenvolvimento deve considerar a mitigação dos impactos ecológicos com os conceitos de biodiversidade e integridade de ecossistemas. Esses efeitos ecológicos envolvem principalmente questões relativas à degradação do solo, às alterações do ciclo hidrológico, às alterações climáticas e à manutenção da biodiversidade.

Diferentes princípios, conceitos e práticas têm sido desenvolvidos com vistas ao desenvolvimento, que, sendo "economicamente viável, socialmente justo e ecologicamente equilibrado" é chamado de sustentável. Variadas concepções envolvem tão abrangentes conceitos, como o que é "socialmente justo" ou o que vem a ser propriamente um ambiente “ecologicamente equilibrado", mas além dessa discussão existe a clara necessidade de se avaliar o impacto exclusivo das atividades humanas no meio ambiente.

No caso dos processos hidrológicos, onde interagem os ciclos biogeoquímicos, o fluxo de energia e os dinâmicos fatores bióticos, em muitos casos têm-se considerado a bacia hidrográfica como a unidade ecossistêmica para estudo e planejamento (Lotspeich, 1980), sendo utilizados diferentes indicadores tais como balanço hídrico, extensão e condição da zona ripária, taxas de infiltração e de erosão do solo, diversidade de invertebrados bentônicos e qualidade da água, para mensurar e avaliar a sustentabilidade das intervenções antropogênicas em métodos de análise multicriterial (Francisco et al., 2008).

Uma zona fundamental para a preservação da qualidade da água e diversificação de habitats em uma bacia hidrográfica é o ecossistema ripário que constitui uma interface entre o ambiente terrestre e o aquático. Esse ambiente ribeirinho reflete um complexo de fatores geológicos, climáticos, hidrológicos que em interação com os fatores bióticos definem uma heterogeneidade de ambientes (Rodrigues, 2000). Sob florestas ciliares ocorre uma significativa variação de solos, cujos reflexos aparecem nos diversos tipos de formações florestais (Jacomine, 2000). As comparações florísticas entre remanescentes de formações florestais ciliares mostram que essas áreas são muito diversas, mesmo em áreas de grande proximidade espacial, e essa diversidade é dependente também, entre outros fatores, do tamanho da faixa ciliar florestada (Metzeger et al., 1997). Esses autores ressaltam que apenas um grande esforço de preservação pode possibilitar a manutenção dessa biodiversidade, no pouco que resta de florestas ciliares, aliado a uma implementação no conhecimento científico sobre essas áreas. A água que flui nos cursos não está isolada e hermética à complexa interação com a área ripária. Em realidade, são sistemas abertos e que participam de todos os processos ecológicos que ocorrem nas bacias hidrográficas, historicamente negligenciados no processo de exploração dos recursos naturais (Barrela et al., 2000).

A preservação da faixa ripária, principalmente nos córregos, é de extrema importância pois evita a erosão de solos adjacentes, impedindo ou atenuando a sedimentação e assoreamento do leito. O assoreamento provoca a perda de habitats aquáticos, o rebaixamento do lençol freático, a diminuição na vazão média e o declínio da biodiversidade do sistema 
COELHO, R. C. T. P.; BUFFON, I.; GUERRA, T. Influência do uso e ocupação do solo na qualidade da água: um método para avaliar a importância da zona ripária. Ambi-Agua, Taubaté, v. 6, n. 1, p. 104-117, 2011. (doi:10.4136/ambi-agua.177)

(Berkman e Rabeni, 1987). A retirada da vegetação das margens dos cursos d’água é prejudicial também porque o material em suspensão interfere na qualidade da água do corpo receptor (Odum, 1988). Em escala de pequenas bacias e sub-bacias hidrográficas, a extensão e condição da mata ciliar podem ser utilizadas como indicadores hidrológicos da sustentabilidade das atividades humanas (Lima e Zákia, 1998), pois a vegetação ripária é responsável por grande parte do regime ambiental do ecossistema aquático (Likens, 1985).

A delimitação da zona ripária é uma das primeiras etapas para a avaliação desta como um indicador, e, em tese, seus limites estendem-se às margens laterais dos corpos d’água até o alcance máximo da zona saturada do solo, que dada a dinâmica dessa zona, aumenta a dificuldade de seu mapeamento. Diferentes métodos de modelagem e mapeamento das zonas ripárias foram desenvolvidos a partir de fatores topográficos e de condutividade do solo, simulando a resposta hidrológica da bacia a uma determinada chuva em modelos digitais (Simões, 2001), entretanto, na legislação brasileira, a zona ripária é estabelecida, na prática, conforme a largura da lâmina dos corpos d’água, sendo protegida como área de preservação permanente (Brasil, 1965). O uso dessa área é permitido em casos de utilidade pública, como obras de infraestrutura, ou no caso de interesse social, como no caso da pequena propriedade agrícola aliada às práticas de manejo sustentável (Brasil, 2000) as quais podem implementar a funcionalidade do sistema, diminuindo a contaminação dos corpos d'água por poluentes antropogênicos (Wallace, 1997).

Mas como avaliar a condição da zona ripária? No caso de toda a bacia, Mancini et al. (2005) avaliaram a condição da bacia de drenagem classificando o uso e cobertura do solo em 4 categorias avaliados com um índice de antropização. Esse índice foi correlacionando com a qualidade biológica da água, avaliada pela diversidade de invertebrados bentônicos. O escopo deste trabalho foi desenvolver um método unicriterial de avaliação da zona ripária com enfoque no uso do solo, avaliado com um índice de antropização adaptado e correlacionado com a qualidade físico-química da água corrente, considerando-se como zona ripária aquela estritamente estabelecida na legislação brasileira como área de preservação permanente ripária.

\section{MATERIAIS E MÉTODOS}

Este estudo foi realizado na área de influência da Floresta Nacional de Canela (Figura 1), uma área de proteção ambiental localizada na fitofisionomia denominada como floresta ombrófila mista, na bacia hidrográfica do rio Caí (veja Coelho (2008) para uma maior descrição), no período de julho de 2006 a junho de 2007. Limitou-se a análise a 8 sub-bacias, e respectivas zonas ripárias, da mesma região assim diminuindo-se as influências relacionadas às variáveis climáticas, edáficas e fitofisionômicas. As áreas das sub-bacias variaram de 20 a 592 ha, em que 37,5\% eram menores a 50 ha, 37,5\% com tamanho entre 50 e 100 ha, 12,5\% com área de aproximadamente 200 ha e outros 12,5\% com uma sub-bacia de 600 ha aproximadamente. 
COELHO, R. C. T. P.; BUFFON, I.; GUERRA, T. Influência do uso e ocupação do solo na qualidade da água: um método para avaliar a importância da zona ripária. Ambi-Agua, Taubaté, v. 6, n. 1, p. 104-117, 2011.
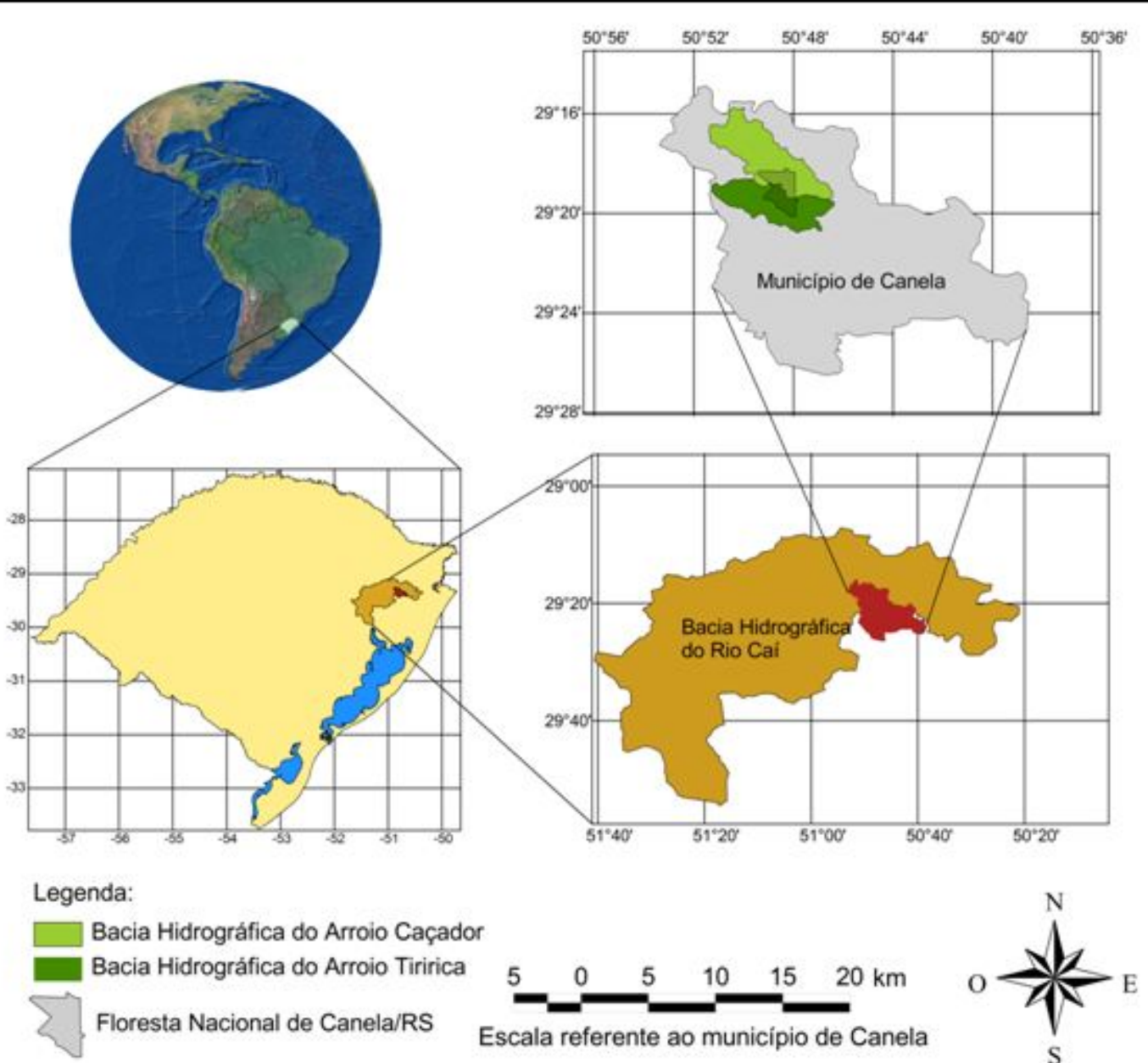

Figura 1. Mapa de localização das bacias hidrográficas do rio Caí, dos arroios Caçador e Tiririca e a situação da Floresta Nacional de Canela, no município de Canela (a escala na figura se refere ao município de Canela, no quadro superior direito).

As sub-bacias drenam áreas dentro da área protegida da Floresta Nacional e em áreas vizinhas que pertencem aos arroios Tiririca e Caçador, inseridos nas cabeceiras da bacia hidrográfica do rio Caí.

Para a obtenção dos dados de terreno que serviram para compor a base cartográfica, realizou-se a vetorização da carta do exército de Canela, Folha SH. 22-X-C-I-3, previamente georreferenciada com um RMS inferior a 0,5 pixel na escala 1:50.000 (Brasil, 1980). Na criação da base cartográfica foi utilizado o aplicativo CartaLinx (Clark Labs, 1999) por possibilitar, além da vetorização dos objetos, a criação de um banco de dados com atributos de qualificação e a delimitação da área das bacias hidrográficas considerando as curvas de nível encontradas na base cartográfica. Neste trabalho, o divisor topográfico foi considerado como o divisor de águas das bacias devido à dificuldade de determinar precisamente o divisor freático e porque somente em situações de rebaixamento do lençol subterrâneo, durante períodos de estiagem, é que o divisor freático distancia-se significativamente do topográfico (Villela e Mattos, 1975).

Para a identificação dos tipos predominantes de ocupação e uso do solo analisou-se uma imagem multiespectral do satélite LANDSAT-TM, ano base 2003, com resolução espacial de 30 metros e composição RGB 453. Essa imagem foi georreferenciada, utilizando-se o módulo RESAMPLE do software IDRISI (Clark Labs, 2003). No módulo RESAMPLE foram utilizados 12 pontos de controle retirados da base cartográfica. Esses pontos controle são compostos por pontos da base cartográfica facilmente identificáveis na imagem de satélite 
COELHO, R. C. T. P.; BUFFON, I.; GUERRA, T. Influência do uso e ocupação do solo na qualidade da água: um método para avaliar a importância da zona ripária. Ambi-Agua, Taubaté, v. 6, n. 1, p. 104-117, 2011. (doi:10.4136/ambi-agua.177)

como, por exemplo, entroncamentos de cursos d’água, entroncamentos de estrada e represamentos de água.

Nessa classificação, consideraram-se cinco categorias de ocupação e uso do solo: floresta nativa, floresta exótica, campo, agropecuária e área urbanizada. Classificaram-se as imagens pelo método manual, o que consistiu na interpretação visual dos alvos na tela do computador e na digitalização (Pinheiro e Kux, 2005). Realizou-se a vetorização das classes com o software CartaLinx e se calcularam as áreas de cada classe de ocupação do solo pelo módulo AREA do software IDRISI.

Utilizaram-se os dados da classificação do uso e ocupação do solo para a composição de um índice de antropização (Ia) para cada sub-bacia de drenagem, situadas a montante dos locais de amostragem de água. O índice de antropização utilizado é uma adaptação do índice utilizado por Mancini et al. (2005) e calculado conforme a seguinte equação:

$$
I a=\Sigma k_{i} p_{i}
$$

Em que $\boldsymbol{I} \boldsymbol{a}$ é o índice de antropização, $\boldsymbol{\Sigma}$ indica o somatório de $\boldsymbol{k}_{\boldsymbol{i}}$, que é o coeficiente específico para cada categoria de uso e ocupação do solo, multiplicado por $\boldsymbol{p}_{\boldsymbol{i}}$, que é a frequência relativa da área de cada categoria. Atribuíram-se valores arbitrários para $\boldsymbol{k}$ considerando-se que quanto mais uma área sofre alteração antrópica, mais a vegetação difere de seu clímax e aumenta a taxa de escoamento superficial com o incremento na exportação de materiais (sedimentos, agrotóxicos, fertilizantes, água, detergentes) para os cursos d’água. Os valores de $\boldsymbol{k}$ apresentam uma proporcionalidade entre si em correspondência com os valores do coeficiente de escoamento superficial $C$ estabelecido pela prefeitura de São Paulo (Wilken 1978 apud Tucci, 2002). Portanto os seguintes valores $\boldsymbol{k}$ foram atribuídos para as categorias de uso e ocupação do solo: 0,5 - áreas inundáveis; 1,0 - floresta nativa; 2,0 - floresta exótica; 3,0 - campos naturais; 4,0 - áreas de agropecuária; 5,0 - áreas urbanas ou industriais. Enquanto que o maior valor $\boldsymbol{k}$ foi estabelecido para as áreas urbanas e industriais, o menor valor foi atribuído para a ocupação de áreas inundáveis, pois essa é uma categoria de ocupação considerada como área de preservação permanente dada a sua importância no ciclo hidrológico (Brasil, 1965). Consideraram-se duas categorias distintas para a cobertura florestal nativa e outra para a floresta exótica por terem diferentes características de cobertura do solo ocasionando diferentes taxas de escoamento superficial. Na categoria floresta exótica, considerando-se somente a cobertura do solo, o escoamento é superior à floresta nativa, pois as práticas da silvicultura local utilizam uma maior densidade de árvores que diminuem a luminosidade no sub-bosque, principalmente no primeiro decênio de cultivo (Aussenac, 2000). O maior sombreamento ocasiona uma diminuição na cobertura do solo por plantas, principalmente das espécies de gramíneas que possuem a fotossíntese com o ciclo do ácido dicarboxílico C4, e estas requerem uma maior energia luminosa e temperatura para seu pleno desenvolvimento (Odum, 1988).

Caracterizou-se a faixa da área de preservação permanente (APP) ripária dos cursos d'água considerando-se como APP a área ao longo dos cursos d'água em uma faixa marginal desde o seu nível mais alto, com uma largura mínima de 30 metros, conforme a legislação federal (Brasil, 1965). Na referida legislação ambiental constam cinco classes de largura da faixa de preservação permanente ripária relacionadas à largura do curso d’água. Embora essa relação possa sub-dimensionar e em outros casos sobre-dimensionar a zona ripária, adotaramse aqui os limites das zonas ripárias análogos aos limites das áreas de preservação permanente - APP da zona ribeirinha, que coincide com a faixa recomendada para a estabilidade do canal em cursos de pequena ordem (Rabeni, 1991 apud Large e Petts, 1992).

Em expedições a campo procedeu-se ao caminhamento de toda a extensão do curso d’água principal de cada sub-bacia, desde as nascentes até o exutório da respectiva sub-bacia, local de coleta de amostras de água. Em todo percurso, levantaram-se os dados de classes de 
COELHO, R. C. T. P.; BUFFON, I.; GUERRA, T. Influência do uso e ocupação do solo na qualidade da água: um método para avaliar a importância da zona ripária. Ambi-Agua, Taubaté, v. 6, n. 1, p. 104-117, 2011. (doi:10.4136/ambi-agua.177)

uso e ocupação do solo da faixa de APP de ambas as margens dos cursos d'água com uma resolução espacial de trechos de $10 \mathrm{~m}$ de largura por $10 \mathrm{~m}$ de extensão. Cada trecho foi georreferenciado com receptor GPS operado no sistema de referência UTM e datum horizontal Córrego Alegre, Minas Gerais. Toda a composição dos trechos foi plotada sobre a base cartográfica, e as respectivas características estruturadas em banco de dados para o cálculo de áreas e distâncias com o software CartaLinx. Analisou-se a ocupação e uso do solo com o uso do índice de antropização da APP ripária - Ia APP, analogamente à análise das sub-bacias. Inferiu-se a influência da zona ripária na qualidade da água correlacionando o Ia APP, calculado para cada curso d’água, com os respectivos índices de qualidade da água.

Avaliou-se a qualidade da água com o uso de um índice de qualidade da água composto pelos parâmetros potencial hidrogeniônico, saturação de oxigênio dissolvido, concentração de sólidos dissolvidos totais, concentração de sólidos solúveis totais e turbidez, além de parâmetros secundários como vazão, temperatura e condutividade. Coletaram-se amostras d’água em oito cursos que fluem na Floresta Nacional de Canela e seu entorno (Figura 2). Também considerou-se a interferência das variações climáticas sazonais na qualidade das águas correntes nessa região com coletas mensais durante o período de um ano (julho de 2006 a junho de 2007).

Para a elaboração de um índice de qualidade da água adaptou-se o Índice de Qualidade da Água - IQA desenvolvido pela NSF - National Sanitation Foundation (CETESB, 2007) e as equações utilizadas por Bendati et al.(2003), ajustando-se os pesos (Tabela 1) com o critério de um gradiente entre o ponto de controle branco, ou água sem contaminação antrópica (T8), e o ponto de controle negro, ou água mais poluída (T4). Apesar da utilização de um índice de qualidade apresentar perda de informação das variáveis individuais e da interação entre elas, as principais vantagens da utilização de um índice são a facilidade de interpretação com o público não técnico e o fato de representar uma média de diversas variáveis em um único número, combinando unidades de medidas diferentes em uma única unidade (CETESB, 2007). Utilizou-se o modelo de IQA com uma escala de 0 a 100, com a seguinte fórmula:

$$
I Q A=\Pi q i^{w i}
$$

Em que $\boldsymbol{\Pi}$ é o símbolo do produtório; qi é a qualidade do i-ésimo parâmetro; $\boldsymbol{w}$ é o peso relativo do i-ésimo parâmetro; $\boldsymbol{i}$ é o número de ordem do parâmetro.

Tabela 1. Qualidade relativa (q) para cada parâmetro avaliado e peso relativo na composição do IQA local.

\begin{tabular}{|c|c|c|}
\hline Parâmetro & Equação ajustada & Peso relativo \\
\hline Oxigênio dissolvido (\%) & $\begin{array}{l}\mathrm{q}=2,982+0,338879 * \mathrm{OD}+0,0003415 * \mathrm{OD}^{3}-3,094 * \\
10^{-6} * \mathrm{OD}^{4}+2,6476 * 10^{-13} * \mathrm{OD}^{7}\end{array}$ & 0,30 \\
\hline Potencial hidrogeniônico (pH) & $\begin{array}{l}\mathrm{q}=\exp \left(-0,0131 *(\mathrm{pH})^{3}+2,5278 * 10^{-5} * \exp (\mathrm{pH})+\right. \\
\left.1,38718 *(\ln (\mathrm{pH}))^{3}-1,871314 * \ln (\ln (\mathrm{pH}))\right)\end{array}$ & 0,13 \\
\hline Turbidez (UNT) & $\begin{array}{l}\mathrm{q}=\exp \left(4,567765-0,0209573 *(\text { Turb. })+4,1215 * 10^{-5} *\right. \\
\left.(\text { Turb. })^{2}-5,319846 * 10^{-8} *(\text { Turb. })^{3}\right)\end{array}$ & 0,26 \\
\hline Sólidos dissolvidos totais (mg. $\mathrm{L}^{-1}$ ) & $\begin{array}{l}\mathrm{q}=\exp \left(4,404+0,0011838 * \mathrm{SDT}-9,1605 * 10^{6} * \mathrm{SDT}^{2}+\right. \\
\left.6,48885 * 10^{-9} * \mathrm{SDT}^{3}\right)\end{array}$ & 0,09 \\
\hline Sólidos suspensos totais (mg. $\mathrm{L}^{-1}$ ) & $\mathrm{q}=100 * \exp (-0,0579 * \mathrm{SST})$ & 0,22 \\
\hline
\end{tabular}


COELHO, R. C. T. P.; BUFFON, I.; GUERRA, T. Influência do uso e ocupação do solo na qualidade da água: um método para avaliar a importância da zona ripária. Ambi-Agua, Taubaté, v. 6, n. 1, p. 104-117, 2011. (doi:10.4136/ambi-agua.177)

\section{RESULTADOS E DISCUSSÃO}

A interpretação das imagens e a delimitação das bacias hidrográficas e sub-bacias de drenagem demonstraram quatro categorias principais de uso e ocupação do solo: floresta nativa; agropecuária; floresta exótica e urbana (Tabela 2). A categoria referente a campo não foi identificada nessas sub-bacias, sendo que pequenas áreas de pastagens associadas às áreas de cultivo ficaram classificadas na categoria de agropecuária.

Tabela 2. Uso e ocupação do solo nas áreas das sub-bacias (SB) e nas áreas de preservação permanente ripárias (APP), e respectivos índices de antropização (Ia) e de qualidade da água (IQA).

\begin{tabular}{|c|c|c|c|c|c|c|c|c|c|}
\hline $\begin{array}{c}\text { Sub- } \\
\text { bacia }\end{array}$ & Área & $\begin{array}{c}\text { Áreas } \\
\text { inundáveis } \\
(\%)\end{array}$ & $\begin{array}{c}\text { Floresta } \\
\text { nativa (\%) }\end{array}$ & $\begin{array}{c}\text { Floresta } \\
\text { exótica (\%) }\end{array}$ & $\begin{array}{c}\text { Campos } \\
(\%)\end{array}$ & $\begin{array}{c}\text { Agrope-cuária e } \\
\text { desflorestamento } \\
\text { (\%) }\end{array}$ & $\begin{array}{l}\text { Áreas } \\
\text { urbanas } \\
(\%)\end{array}$ & $\begin{array}{c}\text { Ia } \\
(0 \text { a } 5)\end{array}$ & $\begin{array}{c}\text { IQA } \\
(0 \text { a 100) }\end{array}$ \\
\hline \multirow{2}{*}{ C1 } & SB & 0,0 & 48,8 & 51,2 & 0,0 & 0,0 & 0,0 & 1,5 & \multirow{2}{*}{84} \\
\hline & APP & 0,0 & 100,0 & 0,0 & 0,0 & 0,0 & 0,0 & 1,0 & \\
\hline \multirow{2}{*}{ C2 } & SB & 0,0 & 48,2 & 14,2 & 0,0 & 35,1 & 2,4 & 2,4 & \multirow{2}{*}{87} \\
\hline & APP & 4,1 & 63,6 & 7,7 & 2,0 & 13,4 & 9,2 & 1,9 & \\
\hline \multirow{2}{*}{$\mathrm{T} 1$} & SB & 0,0 & 47,9 & 23,9 & 0,0 & 6,4 & 21,8 & 2,3 & \multirow{2}{*}{81} \\
\hline & APP & 15,2 & 44,3 & 10,3 & 7,2 & 7,8 & 15,3 & 2,0 & \\
\hline \multirow{2}{*}{ T2 } & SB & 0,0 & 76,4 & 0,0 & 0,0 & 0,0 & 23,6 & 1,9 & \multirow{2}{*}{54} \\
\hline & APP & 33,4 & 11,2 & 0,0 & 0,0 & 0,0 & 55,3 & 3,0 & \\
\hline \multirow{2}{*}{ T3 } & SB & 0,0 & 21,6 & 0,0 & 0,0 & 0,0 & 78,4 & 4,1 & \multirow{2}{*}{59} \\
\hline & APP & 43,4 & 25,7 & 0,0 & 1,3 & 3,8 & 25,8 & 2,0 & \\
\hline \multirow{2}{*}{ T4 } & SB & 0,0 & 59,1 & 0,0 & 0,0 & 0,0 & 40,9 & 2,6 & \multirow{2}{*}{41} \\
\hline & APP & 0,0 & 0,0 & 0,0 & 0,0 & 0,0 & 100,0 & 5,0 & \\
\hline \multirow{2}{*}{ T5 } & SB & 0,0 & 57,4 & 0,0 & 0,0 & 0,0 & 42,6 & 2,7 & \multirow{2}{*}{73} \\
\hline & APP & 9,5 & 8,3 & 9,1 & 40,1 & 0,0 & 32,9 & 3,2 & \\
\hline \multirow{2}{*}{ T8 } & SB & 0,0 & 58,7 & 41,3 & 0,0 & 0,0 & 0,0 & 1,4 & \multirow{2}{*}{87} \\
\hline & APP & 0,3 & 0,0 & 99,7 & 0,0 & 0,0 & 0,0 & 2,0 & \\
\hline \multirow{2}{*}{ Total } & SB & 0,0 & 44,6 & 18,3 & 0,0 & 21,6 & 15,5 & 2,5 & \multirow{2}{*}{71} \\
\hline & APP & 12,0 & 45,7 & 10,9 & 6,7 & 6,3 & 18,5 & 2,1 & \\
\hline
\end{tabular}

A categoria de uso e ocupação do solo floresta nativa inclui a floresta ombrófila mista em diferentes estágios sucessionais assim como as clareiras e banhados. Essa é a ocupação predominante nas sub-bacias (Figura 2), cobrindo 44,6\% dos 1.107 ha da área total (Tabela 2). 
COELHO, R. C. T. P.; BUFFON, I.; GUERRA, T. Influência do uso e ocupação do solo na qualidade da água: um método para avaliar a importância da zona ripária. Ambi-Agua, Taubaté, v. 6, n. 1, p. 104-117, 2011. (doi:10.4136/ambi-agua.177)

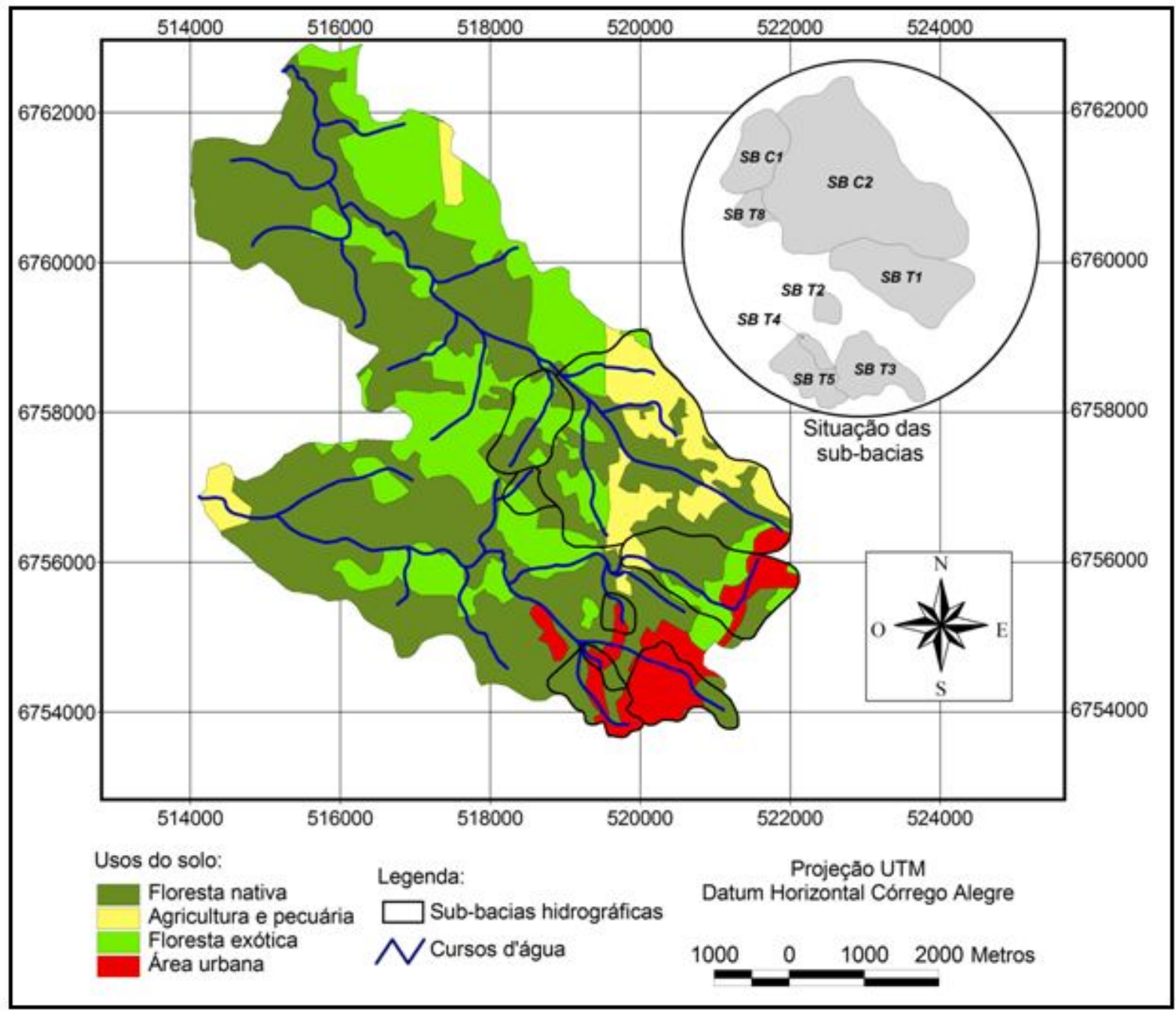

Figura 2. Uso e ocupação do solo nas sub-bacias hidrográficas dos arroios Caçador e Tiririca.

As áreas de florestas nativas, em decorrência de uma maior cobertura do solo e maiores taxas de infiltração e detenção da água das chuvas, possuem um coeficiente de escoamento superficial $\mathrm{C}$ menor que as demais categorias, quando consideramos textura de solo e declividades similares (Tucci, 2002). O menor escoamento superficial terá consequências sobre a qualidade da água, pois diminui a erosão e lixiviação do solo na bacia e a erosão no próprio leito do curso d'água em decorrência das menores vazões. Os maiores coeficientes de escoamento superficial são encontrados na categoria agropecuária, predominante nas nascentes da bacia hidrográfica do arroio Caçador, e na categoria áreas urbanas, que predomina nas áreas das nascentes da bacia hidrográfica do arroio Tiririca.

A sub-bacia C1, com 96,8 ha, é uma das sub-bacias avaliadas com cobertura florestal em $100 \%$ de sua área, estando composta por 48,8\% de florestas nativas e 51,2\% de florestas exóticas. A diminuição no desenvolvimento das gramíneas, como as taquaras da espécie Guadua tagoara existentes na área (Ramos et al., 2008), e uma cobertura do solo composta predominantemente por acículas, aumentam a taxa de escoamento superficial, sendo essa taxa maior que a encontrada na floresta nativa em decorrência da diversidade de ocupação do solo observada no sub-bosque.

A sub-bacia C2 é composta por 592,3 ha da bacia hidrográfica do arroio Caçador que apesar de apresentar quase a metade de sua área com cobertura florestal nativa (48,2\%) e mais 14,2\% de cobertura florestal exótica, possui 35,1\% de áreas agrícolas e 2,4\% de áreas urbanizadas. As áreas agrícolas estão localizadas principalmente nas áreas mais planas localizadas a montante e utilizadas principalmente com cultivo de macieiras. As áreas com 
COELHO, R. C. T. P.; BUFFON, I.; GUERRA, T. Influência do uso e ocupação do solo na qualidade da água: um método para avaliar a importância da zona ripária. Ambi-Agua, Taubaté, v. 6, n. 1, p. 104-117, 2011. (doi:10.4136/ambi-agua.177)

fruticultura são áreas agrícolas que possuem baixas taxas de erosão do solo dado o inexistente revolvimento do solo, mas podem comprometer a qualidade da água principalmente pela lixiviação de fertilizantes e agrotóxicos.

Já o uso e ocupação do solo nas APP ripárias resultaram em um maior detalhamento do que a caracterização da ocupação do solo nas sub-bacias, pois o método de levantamento de dados a campo permitiu que fossem observados os usos de solo em áreas pequenas de até $10 \mathrm{~m}^{2}(1 \times 10)$.

O curso C1, com uma extensão total de 1.478 m e uma área de APP com 8,87 ha apresentou dentre as áreas avaliadas a melhor situação, com um índice de antropização de 1,0, o menor valor entre as áreas avaliadas, em uma escala que vai de 0,5 a 5,0. Isso decorre que toda a APP é composta por mata nativa preservada. A maior declividade desse curso propicia uma maior velocidade de escoamento no canal, o que faz com que prepondere o processo de transporte de material sobre o processo de sedimentação, determinando um leito rochoso.

Já o curso C2, que teve a maior extensão entre os cursos avaliados (3.800m) onde se observou grande diversidade de usos de solo na APP, e a mata nativa como a ocupação predominante. Os principais usos conflitantes encontrados foram a urbanização e as áreas desmatadas que compreendem $22 \%$ da área levantada e se concentram na região de nascentes. As alterações da zona da APP e do próprio leito provocam a perda e a degradação de habitats, fatores relevantes que ameaçam a biodiversidade dos cursos (Muotka e Laasonem, 2002).

O curso T1 tem uma extensão total $2.491 \mathrm{~m}$ e sua área de APP totaliza 14,94 ha, apresenta grande diversidade de usos na faixa de APP, todas as classes utilizadas no levantamento tiveram representação nesse curso. A classe de mata nativa foi predominante em 44\% da área ribeirinha, e a área de banhados se iguala à área urbanizada em 15\% cada. Dessa maneira, o somatório das classes floresta nativa e banhados compreendem 59\% das áreas naturais ao longo desse curso d’água.

Para o curso T2, obteve-se um Ia APP de 3,0 muito parecido com o obtido para o curso T5 (Ia APP = 3,2), mas existiram diferenças na qualidade da água com um IQA de 54 para o T2 e IQA 73 para o T5. Essas diferenças possivelmente estão relacionadas às diferentes composições de áreas urbanas.

O curso d'água T3 tem 1.403 m de extensão formada por 70\% de áreas naturais (mata nativa, campo e banhado) e $26 \%$ de áreas urbanas, determinando uma qualidade de água intermediária (IQA = 59). O curso d'água T4 tem $421 \mathrm{~m}$ de extensão e área total de APP de 2,52 ha, apresenta dentre as APP avaliadas a pior situação. Toda sua extensão apresenta urbanização e o leito está confinado em tubulações, recebendo efluentes das residências de entorno e sem quedas d’água que promovam a aeração propícia para a autodepuração.

Quanto ao curso d'água T8, este tem um comprimento de $647 \mathrm{~m}$ e uma APP com 3,88 ha coberta com floresta exótica (Pinus $s p$ ) com mais de 30 anos de cultivo, o que permitiu o desenvolvimento de um sub-bosque com regeneração da mata nativa em $100 \%$ da área ripária. Observamos que áreas vegetadas com gramíneas, características da classe campos, e frequentes na área ripária do curso T5, são menos eficientes que as áreas florestadas na redução das concentrações de alguns poluentes como os nitratos. A restauração dessas áreas com árvores e arbustos é essencial para melhorar a qualidade da água corrente (Osborne e Kovacic, 1993).

O desenvolvimento de florestas na área ripária, funcionando como área tampão, tem sido muito recomendado para implementar a qualidade da água superficial, mas também há alguns autores que verificaram que algumas composições de arbustos e gramíneas foram eficientes na melhoria da qualidade da água em faixas estreitas de apenas $8 \mathrm{~m}$, principalmente quando aliadas a incrementos na taxa de infiltração (Mankin et al., 2007). Estudos que avaliem a eficiência de outras formações e estruturas da vegetação ciliar são importantes pois podem possibilitar o uso sustentável dessas áreas. 
COELHO, R. C. T. P.; BUFFON, I.; GUERRA, T. Influência do uso e ocupação do solo na qualidade da água: um método para avaliar a importância da zona ripária. Ambi-Agua, Taubaté, v. 6, n. 1, p. 104-117, 2011. (doi:10.4136/ambi-agua.177)

A elaboração de um índice de qualidade da água adaptado a um menor número de parâmetros monitorados e à situação local resultou em um IQA máximo para os cursos T8 (ponto controle) e C2 (arroio Caçador) ambos com IQA = 87, denotando uma classificação de qualidade boa (TABELA 2). O arroio Caçador (C2) é o que apresenta o maior índice de qualidade da água $(\mathrm{IQA}=87,4)$, pouco superior ao córrego T8 $(\mathrm{IQA}=87,2)$, em decorrência da baixa concentração média de sólidos suspensos totais $\left(6,5 \mathrm{mg} \cdot \mathrm{L}^{-1}\right)$, baixa turbidez média de 5,10 UNT, pequena concentração de sólidos dissolvidos média $\left(10 \mathrm{mg} . \mathrm{L}^{-1}\right)$ e pela alta saturação de oxigênio dissolvido (94,45\%).

Encontrou-se o valor mínimo para o curso T4 com IQA $=41$, correspondendo a uma qualidade ruim, conforme as faixas de qualidade de água para o IQA do NSF. O córrego T4 é o que apresenta o mais baixo índice de qualidade da água, em decorrência da alta concentração de sólidos suspensos totais média $\left(29,3\right.$ mg. $\left.\mathrm{L}^{-1}\right)$, alta turbidez média de 39,61 UNT, alta concentração de sólidos dissolvidos média (100 mg. $\left.\mathrm{L}^{-1}\right)$ e baixa saturação de oxigênio dissolvido média (58,22\%).

Uma maior densidade de quedas d'água e maiores alturas das quedas, provavelmente, são os fatores determinantes no aumento da concentração do oxigênio dissolvido e a autodepuração no arroio Caçador - C2 (Coelho, 2008). O maior peso dado ao parâmetro OD contribuiu para que esse arroio se equivalesse à qualidade da água do ponto de controle T8, que é o córrego que flui uma água límpida em um canal sombreado e com poucas quedas, fatores que não favorecem uma maior concentração de OD. Diferentes autores têm demonstrado a influência das cascatas naturais no processo de reaeração das águas dos córregos (Von Sperling, 1996; Giansante, 1997; Butts e Evans, 1984), onde além da velocidade e turbulência do fluxo (Giansante, 1985; Kucukali e Cokgor, 2006), um dos componentes principais no processo de reaeração mais evidenciado é a altura da queda d'água. Para uma futura adequação do índice ao local sugere-se que seja dado um menor peso para o parâmetro OD, e um aumento na ponderação dos parâmetros SDT e turbidez.

Quando se testou a correlação (regressão polinomial de $2^{\mathrm{a}}$ ordem) existente entre o índice de antropização das bacias de drenagem - Ia SB com o índice de qualidade da água - IQA, encontrou-se um $\mathrm{R}^{2}$ igual a 0,23 (Figura 3), demonstrando uma correlação negativa entre ambas variáveis. Quando se correlacionou o índice de qualidade da água - IQA, com o índice de antropização da área de preservação permanente - Ia APP, localizada às margens dos cursos d'água, verificou-se uma alta correlação, chegando a um $R^{2}$ superior a 0,64 . Não obstante as limitações dos métodos empregados para o cálculo do IQA e o pequeno número de cursos d’água analisados, a correlação do IQA com o Ia SB é inferior à correlação com o Ia $\operatorname{APP}\left(\left(\mathrm{R}^{2}=0,23\right)<\left(\mathrm{R}^{2}=0,64\right)\right)$, donde depreendemos que o uso e ocupação do solo da APP ripária é preponderante sobre a ocupação do solo na bacia de drenagem na variação da qualidade da água, o que condiz com a ênfase dada às limitações de uso das áreas ribeirinhas pela legislação ambiental (Brasil, 1965).

Em um índice de antropização composto por $60 \%$ do Ia APP e $40 \%$ do Ia SB encontramos a maior correlação polinomial com o Índice de Qualidade da Água $\left(\mathrm{R}^{2}=0,73\right)$, demonstrando que apesar de o uso e ocupação da APP ripária ter a maior influência na qualidade da água, também o uso dado na bacia de drenagem possui um grau de interferência nessa qualidade. 
COELHO, R. C. T. P.; BUFFON, I.; GUERRA, T. Influência do uso e ocupação do solo na qualidade da água: um método para avaliar a importância da zona ripária. Ambi-Agua, Taubaté, v. 6, n. 1, p. 104-117, 2011. (doi:10.4136/ambi-agua.177)

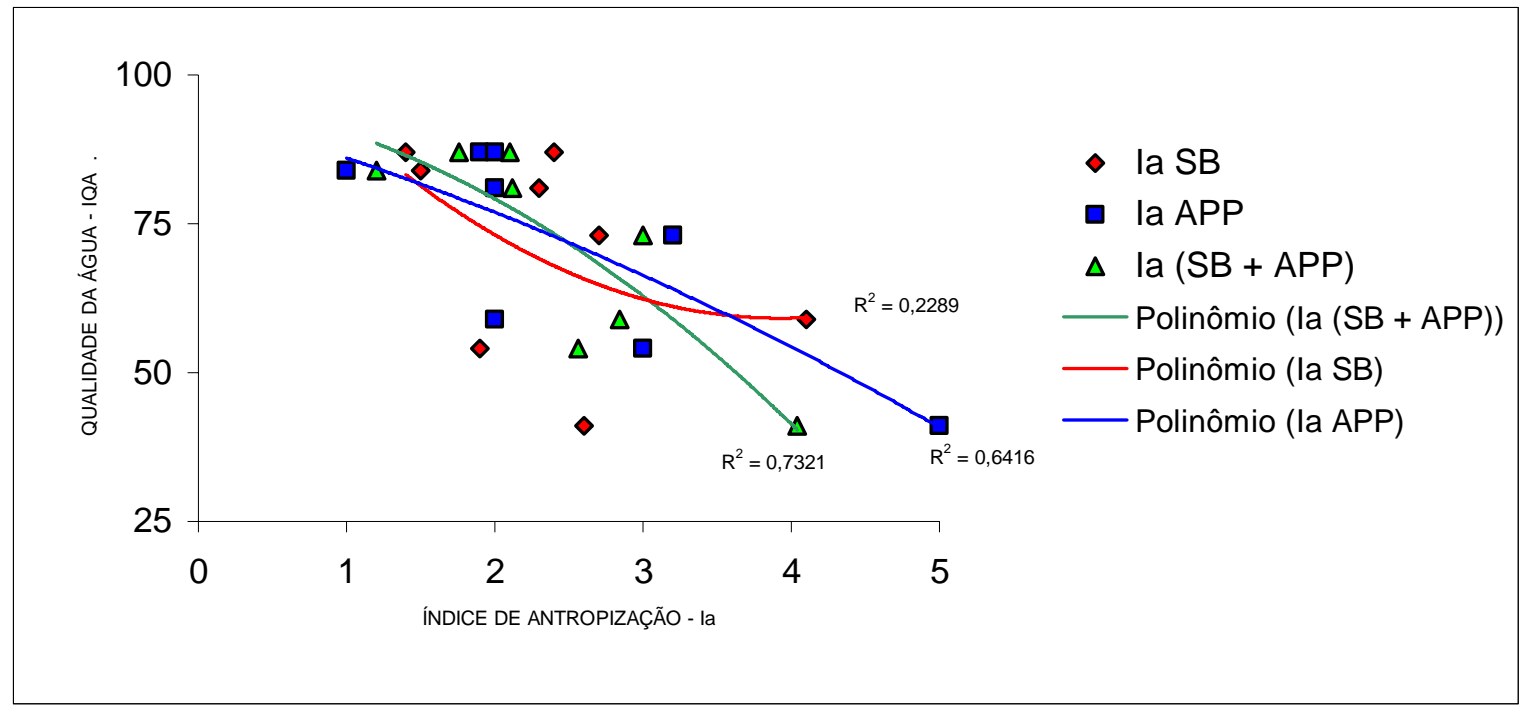

Figura 3. Diagrama de dispersão com as linhas de tendência das correlações entre os índices de antropização - Ia das sub-bacias (vermelho), Ia das APP ripárias (azul) e composto por ambas (verde), com o índice de qualidade da água ( $\mathrm{n}=8$; regressões polinomiais de $2^{\mathrm{a}}$ ordem).

Salienta-se que os resultados encontrados não permitem afirmar que a largura da APP ripária de 30 metros é a mais adequada, pois a largura mais adequada irá depender do enfoque da conservação, Large e Petts (1992) citam várias larguras de zonas ripárias tampão, recomendadas conforme diferentes propósitos, com valores desde $2 \mathrm{~m}$ até $200 \mathrm{~m}$, e as correlações realizadas estão restritas à qualidade da água, desconsiderando-se outros indicadores ambientais como a situação de ocupação do solo imediatamente além da largura da APP, a conectividade biológica e a diversidade de habitats.

Para o aperfeiçoamento do método, supõe-se que o uso de uma melhor resolução da imagem, um maior número de unidades amostrais e a consideração da distância relativa de cada trecho da APP ao local de amostragem da água, podem permitir uma maior acurácia na sentença de conclusões. No modelo utilizado, por exemplo, não está considerado que a proximidade de um banhado pode exercer uma maior influência na qualidade da água do que quando localizado distante ou a montante de uma zona urbanizada, mas, por outro lado, o enfoque macroecológico do método utilizado, incorpora muitas variáveis não mensuradas, resultando numa simplificação da análise ambiental.

\section{CONCLUSÕES}

Não se observou a interferência da variação climática sazonal na qualidade da água, mas constatou-se que a qualidade físico-química da água é preponderantemente influenciada pelas características de ocupação do solo da zona ripária em comparação com a influência da ocupação da respectiva bacia de drenagem.

\section{AGRADECIMENTOS}

Os autores agradecem a cooperação da equipe de profissionais da Floresta Nacional de Canela - ICMBio (Ewerton Ferraz, Paulo Rossi, Lourdes Tomazi, Lourdes Lawarenz, Rita Goulart e Helena Groulke) e ao IBAMA pela concessão de licença de capacitação profissional ao primeiro autor para realização desta pesquisa. 


\section{REFERÊNCIAS BIBLIOGRÁFICAS}

AUSSENAC, G. Interactions between forest stands and microclimate: ecophysiological aspects and consequences for silviculture. Annals of Forest Science, Versailles, v. 57, p. $287-301,2000$.

BARRELA, W.; PETRERE JR., M.; SMITH, W. S.; MONTAG, L. F. As relações entre as matas ciliares, os rios e os peixes. In: RODRIGUES, R. R.; LEITÃO FILHO, H. F. Matas ciliares: conservação e recuperação. São Paulo: FAPESP, 2000. p. 187-208.

BENDATI, M. M.; SCHWARZBACH, M. S. R.; MAIZONAVE, C. R. M.; ALMEIDA, L. B.; BRINGHENTI, M. L. Avaliação da qualidade da água do Lago Guaíba. Rev. Ecos Pesquisa, Porto Alegre, v. 4, n. 7, p. 34, 2003.

BERKMAN, H. E.; RABENI, C. F. Effect of siltation on stream fish communities. Environmental Biology of Fishes, v. 18, n. 4, p. 285-294, 1987. http://dx.doi.org/10.1007/BF00004881

BRASIL. Lei federal $n^{0}$ 4.771, de 15 de setembro de 1965. Institui o novo Código Florestal, alterado pela Lei 7.803, de 18 de julho de 1989. Diário Oficial da República Federativa do Brasil, Brasília, DF, 16 de setembro de 1965.

BRASIL. Medida Provisória n ${ }^{\circ}$.166-67, de 24 de agosto de 2001. Altera os arts. $1^{\circ}, 4^{\circ}, 14$, 16 e 44, e acresce dispositivos à Lei no 4.771, de 15 de setembro de 1965, que institui o Código Florestal, bem como altera o art. 10 da Lei no 9.393, de 19 de dezembro de 1996, que dispõe sobre o Imposto sobre a Propriedade Territorial Rural - ITR, e dá outras providências. Diário Oficial da República Federativa do Brasil, Brasília, DF, 19 de julho de 2000.

BRASIL. Ministério do Exército. Diretoria de Serviço Geográfico. Cartas topográficas de Canela. Brasília: Departamento de Engenharia e Comunicações, 1980. Folha SH. 22-XC-I-4 MI - 2954/3.

BUTTS, T. A.; EVANS, R. L. Small stream channel dam aeration characteristics. Journal of Environmental Engineering, v. 110, p. 728 - 735, 1984. http://dx.doi.org/10.1061/(ASCE)0733-9372(1984)110:3(733)

COMPANHIA DE TECNOLOGIA DE SANEAMENTO AMBIENTAL - CETESB. Relatório de qualidade das águas interiores do estado de São Paulo 2006. São Paulo: CETESB, 2007. 2 v. (Série Relatórios / Secretaria de Estado do Meio Ambiente, ISSN 0103-4103).

CLARK LABS. CartaLinx Software: the spatial data builder. Versão 1.2. Worcester: Clark Labs, 1999.

CLARK LABS. Idrisi Software: the Kilimanjaro edition. Versão 14.01. Worcester: Clark Labs, 2003.

COELHO, R. C. T. P. Avaliação das bacias hidrográficas dos arroios Caçador e Tiririca na Floresta Nacional de Canela, com ênfase na qualidade da água e ocupação do solo das áreas de preservação permanente ripárias. 2008. 128 p. Dissertação (Mestrado em Ecologia) - Universidade Federal do Rio Grande do Sul, Porto Alegre, 2008. 
COELHO, R. C. T. P.; BUFFON, I.; GUERRA, T. Influência do uso e ocupação do solo na qualidade da água: um método para avaliar a importância da zona ripária. Ambi-Agua, Taubaté, v. 6, n. 1, p. 104-117, 2011. (doi:10.4136/ambi-agua.177)

FRANCISCO, C. E. S.; COELHO, R. M.; TORRES, R. B.; ADAMI, S. F. Análise multicriterial na seleção de bacia hidrográfica para a recuperação ambiental. Ciência Florestal, v. 18, n. 1, p. 1 - 13, 2008.

GIANSANTE, A. E. A influência do índice de turbulência no valor do coeficiente de reaeração dos cursos d'água. 1985. Dissertação (Mestrado em Hidráulica e Saneamento) - Escola de Engenharia de São Carlos, Universidade de São Paulo, São Carlos, 1985.

GIANSANTE, A. E. Avaliação da capacidade de autodepuração do ribeirão Jacaré, Itatiba, São Paulo. In: CONGRESSO DA ASSOCIAÇÃO BRASILEIRA DE ENGENHARIA SANITÁRIA- ABES, 18., setembro 1997, Foz do Iguaçu. Anais... ABES: Foz do Iguaçu, 1997.

JACOMINE, P. K. T. Solos sob matas ciliares. In: RODRIGUES, R. R.; LEITÃO FILHO, H. F. Matas ciliares: conservação e recuperação. São Paulo: FAPESP, 2000. p. 27-32.

KUCUKALI, S.; COKGOR, S. Aeration performance of a hydraulic jump. In. WORLD ENVIRONMENTAL AND WATER RESOURCES CONGRESS, May 21-25, 2006, Omaha. Proceedings... Omaha: Randall Graham; ASCE, 2006.

LARGE, A. R.; PETTS, G. E. Rehabilitation of river margins. Chap. 21. In: CALOW, P.; PETTS, G. E. (Eds.). The river handbook hidrological and ecological principles. Oxford: Balckwell Scientific Publications, 1992. p. 401-418.

LIKENS, G. E. An experimental approach for the study of ecosystems. Journal of ecology, v. 73, p. $381-396,1985$. http://dx.doi.org/10.2307/2260481

LIMA, W. P.; ZÁKIA, M. J. B. Indicadores hidrológicos em áreas florestais. Série Técnica IPEF, Piracicaba, v. 12, n. 31, p. 53 - 64, 1998.

LOTSPEICH, F. B. Watersheds as the basic ecosystem: this conceptual framework provides a basis for a natural classification system. Water Resources Bulletin, v. 16, n. 4, p. 581586, 1980.

MANCINI, L.; FORMICHETTI, P.; ANSELMO, A.; TANCIONI, L.; MARCHINI, S.; SORACE, A. Biological quality of running waters in protected areas: the influence of size and land use. Biodiversity and Conservation, n. 14, p. 351-364, 2005. http://dx.doi.org/10.1007/s10531-004-5355-8

MANKIN, K. R.; NGANDU, D. M.; BARDEM, C. J.; HUTCHINSON, S. L.; GEYER, WAYNE A. Grass-shrub riparian buffer removal of sediments, phosphorus and nitrogen from simulated runoff. Journal of the American Water Resources Association, v. 43, n. 5, p. $1108-1116,2007$. http://dx.doi.org/10.1111/j.1752-1688.2007.00090.x

METZEGER, J. P.; BERNACCI, L. C.; GOLDENBERG, R. Pattern of tree species diversity in riparian forest fragments of different widths (SE Brazil). Plant Ecology, v. 133, p. $135-152,1997$. http://dx.doi.org/10.1023/A:1009791831294

MUOTKA T.; LAASONEN, P. Ecosystem recovery in restored headwater streams: the role of enhanced leaf retention. Journal of Applied Ecology, v. 39, p. 145 - 156, 2002. http://dx.doi.org/10.1046/j.1365-2664.2002.00698.x 
COELHO, R. C. T. P.; BUFFON, I.; GUERRA, T. Influência do uso e ocupação do solo na qualidade da água: um método para avaliar a importância da zona ripária. Ambi-Agua, Taubaté, v. 6, n. 1, p. 104-117, 2011. (doi:10.4136/ambi-agua.177)

ODUM, E. Fundamentos de ecologia. 4. ed. Lisboa: Fundação Calouste Gulbenkian, 1988. $403 \mathrm{p}$.

OSBORNE, L. L.; KOVACIC, D. A. Riparian vegetated buffer strips in water-quality restoration and stream management. Freshwater Biology, v. 29, n. 2, p. $243-258$, 1993.

http://dx.doi.org/10.1111/j.1365-2427.1993.tb00761.x

PINHEIRO, E. S.; KUX, H. J. H. Dados do satélite QUICKBIRD para o mapeamento do uso e cobertura da terra numa seção da Mata Atlântica no Estado do Rio Grande do Sul. In: SIMPÓSIO BRASILEIRO DE SENSORIAMENTO REMOTO, 12., 2005, Goiânia. Anais... São José dos Campos: INPE, 2005. p. 4509 - 4516.

RAMOS, A. J. K.; MALUF, R. W.; BOCCHESE, C. A.; VELLOSO, C. C.; SOARES, M. A.; PAULUS, G. et al. Plantas com potencial medicinal na Floresta Nacional de Canela e comunidades do entorno, Canela, Rio Grande do Sul. Porto Alegre: EMATER/ASCAR, 2008. 90 p.

RODRIGUES, R. R. Uma discussão nomenclatural das formações ciliares. In: RODRIGUES, R. R.; LEITÃO FILHO, H. F. Matas ciliares: conservação e recuperação. São Paulo: FAPESP, 2000. p. 91-100.

SIMÕES, L. B. Integração entre um modelo de simulação hidrológica e sistema de informação geográfica na delimitação de zonas tampão ripárias. 2001. 171 p. Tese (Doutorado em Agronomia) - Universidade Estadual Paulista, Botucatu, 2001.

TUCCI, C. E. M. Vazão máxima e hidrograma de projeto. In: Hidrologia: ciência e aplicação. 3. ed. Porto Alegre: Editora da Universidade Federal do Rio Grande do Sul / ABRH, 2002. p. 527 - 568.

VILLELA, S. M.; MATTOS, A. Hidrologia aplicada. São Paulo: McGraw-Hill do Brasil, 1975. 245 p.

VON SPERLING, M. Introdução à qualidade das águas e ao tratamento de esgotos. In: Princípios do tratamento biológico de águas residuárias. Belo Horizonte: Departamento de Engenharia Sanitária e Ambiental; Universidade Federal de Minas Gerais, 1996. 243 p. V. 1.

WALLACE, J. B.; EGGERT, S. L.; MEYER, J. L.; WEBSTER, J. R. Multiple trophic levels of a forest stream linked to terrestrial litter inputs. Science, v. 277, p. 102-104, 1997. http://dx.doi.org/10.1126/science.277.5322.102

WORLD COMMISSION ON ENVIRONMENT AND DEVELOPMENT. Our common future. Oxford: Oxford University Press, 1987. 